\title{
Stereochemical determination of a new and cytotoxic euphane triterpenoid from the plant endophytic fungus Phomopsis chimonanthi
}

\author{
Yonggang Zhang ${ }^{1,6}$, Fang $\mathrm{Hao}^{2,6}, \mathrm{Na} \mathrm{Liu}^{3}$, Yandong $\mathrm{Xu}^{4}$, Airong $\mathrm{Jia}^{1}$, Zhijun Yang ${ }^{5}$, Xuekui Xia ${ }^{1}$ and \\ Changheng Liu ${ }^{1}$
}

The Journal of Antibiotics (2013) 66, 679-682; doi:10.1038/ja.2013.70; published online 7 August 2013

Keywords: absolute configuration; cytotoxicity; endophyte; euphane triterpenoid; Phomopsis chimonanthi

Endophytes inhabiting the normal plant tissues without causing apparent pathogenic symptoms are attracting considerable attention as sources of biologically active secondary metabolites for pharmaceutical and agricultural industries. ${ }^{1-7}$ Phomopsis spp. are prolific endophytic fungi that produce many different types of compounds, such as six new 10-phenyl-[11] cytochalasans, named cytochalasins $\mathrm{N}-\mathrm{S}$, together with the four known compounds, epoxycytochalasins $\mathrm{H}$ and $\mathrm{J}$, and cytochalasins $\mathrm{H}$ and $\mathrm{J}^{8}$ Three new antibiotic and cytotoxic dicerandrols were isolated from an endophytic fungus P. longicolla of the endangered mint Dicerandra frutescens. ${ }^{9,10}$ During our ongoing chemical investigations of endophytic fungi as sources of new bioactive natural products, a subculture of an isolate of $P$. chimonanthi was grown on solid-substrate fermentation culture. Purification of its crude extract led to the isolation of three compounds, including a new euphane triterpenoid, 3S, 22R, 26trihydroxy-8, 24E-euphadien-11-one (1), together with two known compounds, 3-hydroxy-3-phenylpropanoic acid (2) and 3-hydroxy-3(4-hydroxyphenyl) propanoic acid (3) (Figure 1). In this paper, the planar structure, relative and absolute configurations of the new compound are presented in detail. Also, compound $\mathbf{1}$ was evaluated for cytotoxic activities against three human cancer cell lines.

The culture of $P$. chimonanthi was isolated from branches of the salt-tolerant wild medicinal plant Tamarix chinensis in the yellow river delta, Dongying, in May 2011. The isolate was identified as P. chimonanthi by one of the authors (AJ) based on the sequence (GenBank Accession number JQ234963) analysis of the internal transcribed spacer (ITS) region of the recombinant DNA, and deposited in the Biology Institute, Shandong Academy of Sciences (Registration No. YG-1), Jinan. The fungal strain was cultured on slants of potato
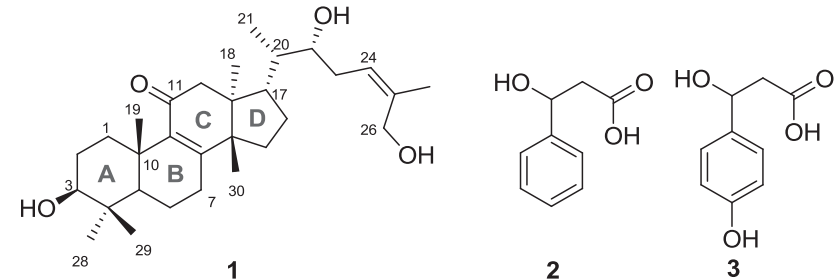

Figure 1 Structures for compounds 1-3. A full color version of this figure is available at The Journal of Antibiotics journal online.

dextrose agar at $28{ }^{\circ} \mathrm{C}$ for 10 days. The agar plugs were inoculated in $250 \mathrm{ml}$ Erlenmeyer flasks, each containing $50 \mathrm{ml}$ of media $(0.4 \%$ glucose, $1 \%$ malt extract and $0.4 \%$ yeast extract), and the final $\mathrm{pH}$ of the media was adjusted to 6.5 before sterilization. Flask cultures were incubated at $28^{\circ} \mathrm{C}$ on a rotary shaker at 170 r.p.m. for 5 days. Fermentation was carried out in four $500 \mathrm{ml}$ Fernbach flasks each containing $80 \mathrm{~g}$ of rice. Spore inoculum was prepared by suspension in sterile, distilled $\mathrm{H}_{2} \mathrm{O}$ to give a final spore/cell suspension of $1 \times 10^{6} \mathrm{ml}^{-1}$. Distilled $\mathrm{H}_{2} \mathrm{O}(100 \mathrm{ml})$ was added to each flask and the contents were soaked overnight before autoclaving at $15 \mathrm{lb} \mathrm{in}{ }^{-1}$ for $30 \mathrm{~min}^{2}$ After cooling to room temperature, each flask was inoculated with $5.0 \mathrm{ml}$ of the spore inoculum and incubated at $28^{\circ} \mathrm{C}$ for 40 days.

The fermented rice substrate was extracted repeatedly with ethyl acetate $(\mathrm{EtOAc})(4 \times 500 \mathrm{ml})$, and the organic solvent was evaporated to dryness under vacuum to afford the crude extract $(5.2 \mathrm{~g})$. The extract was fractionated by Silica gel vacuum liquid chromatography using petroleum ether-EtOAc gradient elution. The fraction (125 mg)

${ }^{1}$ Key Laboratory for Applied Microbiology of Shandong Province, Biotechnology Center of Shandong Academy of Sciences, Jinan, China; ${ }^{2}$ School of Enviromental and Engineering, Shandong University, Jinan, China; ${ }^{3}$ School of Economics and Management, Nanjing University of Information Science \& Technology, Nanjing, China; ${ }^{4}$ Shandong Marine Fisheries Research Institute Yantai, China and ${ }^{5}$ School of Pharmacy, Shanghai Jiaotong University, Shanghai, China

${ }^{6}$ These authors contributed equally to this work.

Correspondence: Dr Y Xu, Biotechnology Center of Shandong Academy of Sciences, Shandong Marine Fisheries Research Institute Yantai, Shandong Province 264006, China. E-mail: xuyandong@163.com

or Professor C Liu, Key Laboratory for Applied Microbiology of Shandong Province, Biotechnology Center of Shandong Academy of Sciences, Jinan 250014, China.

E-mail: liuchh@sdas.org

Received 6 March 2013; revised 25 May 2013; accepted 30 May 2013; published online 7 August 2013 
Table 1 NMR data of 1 (in DMSO- $d_{6}$ )

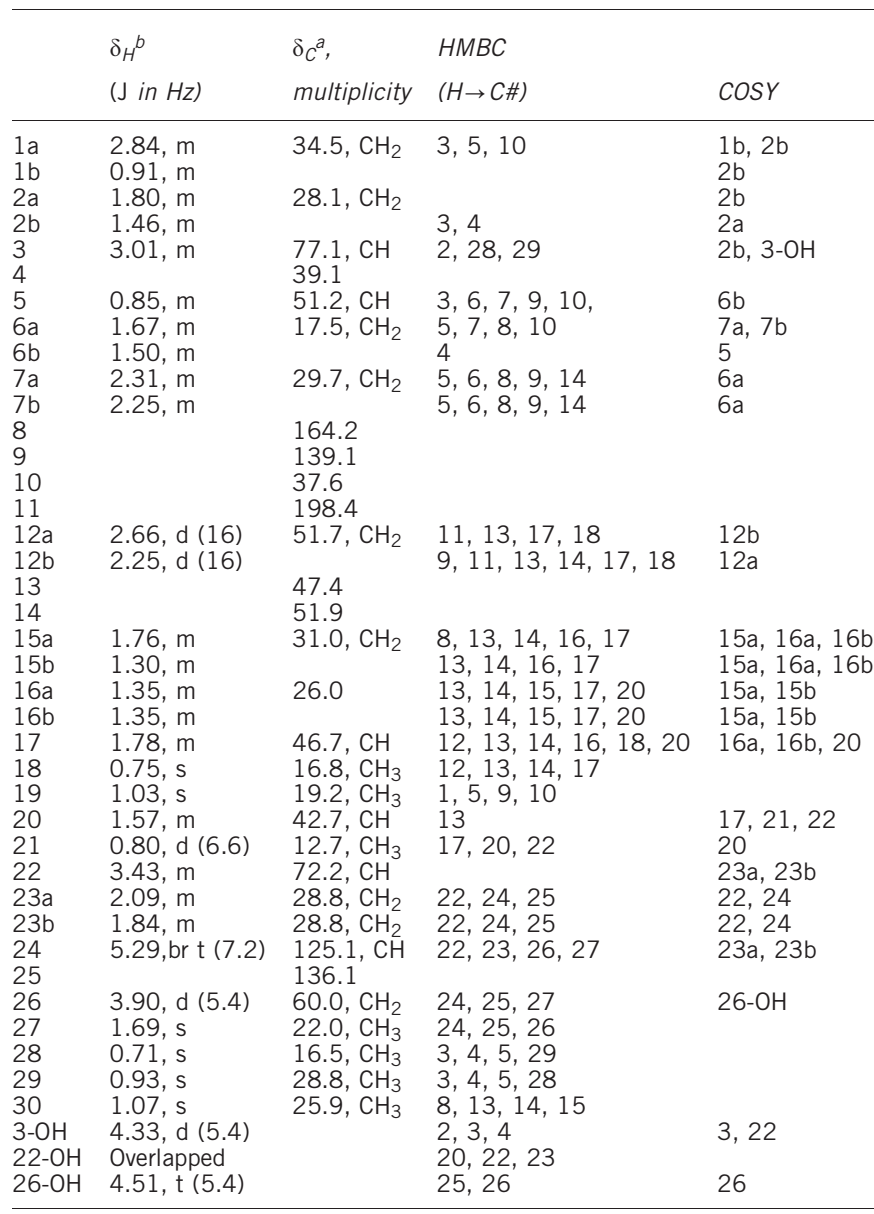

eluted with $80 \%$ EtOAc was separated by Sephadex LH-20 column chromatography and repeatedly eluted with $1: 1 \mathrm{CHCl}_{3}-\mathrm{CH}_{3} \mathrm{OH}$ to give compound 1 ( $5 \mathrm{mg})$. The fraction $(236 \mathrm{mg}$ ) eluted with $8 \%$ EtOAc was separated by Sephadex LH-20 column chromatography eluted with $1: 1 \mathrm{CHCl}_{3}-\mathrm{CH}_{3} \mathrm{OH}$ to obtain compound 2 (10 mg). The fraction $(180 \mathrm{mg}$ ) eluted with $20 \%$ EtOAc was separated by Sephadex LH-20 column chromatography eluted with $1: 1 \mathrm{CHCl}_{3}-\mathrm{CH}_{3} \mathrm{OH}$ to produce compound 3 ( $7 \mathrm{mg}$ ).

${ }^{1} \mathrm{H}$ and ${ }^{13} \mathrm{C}$ NMR data were acquired with Bruker-600 spectrometers using solvent signals (DMSO; $\delta_{\mathrm{H}} 2.50 / \delta_{\mathrm{C}} 39.5$ ) as references. The HMQC and HMBC experiments were optimized for 145.0 and $8.0 \mathrm{~Hz}$, respectively. High resolution electrospray ionization mass spectrometry (HRESIMS) data were acquired using a LTQ Orbitrap XL mass spectrometer (Thermo Fisher, Bremen, Germany). Sephadex LH-20 (Pharmacia Biotech AB, Uppsala, Sweden), silica gel (300-400 mesh) and silica gel GF254 sheets $(0.20-0.25 \mathrm{~mm})$ (both from Qingdao Haiyang Chemical Group, Shandong Province, China) were used for column chromatography and TLC, respectively.

\section{PREPARATION OF (S)-MTPA ( $\alpha$-METHOXY- $\alpha-$ TRIFLUOROMETHYLPHENYLACETIC ACID) ESTER (1A) AND ( $R$ )-MTPA ESTER (1B)}

The complete powder of $\mathbf{1}(1.5 \mathrm{mg})$ was transferred to two small clean bottles, respectively, and then pyridine- $d_{5}(0.5 \mathrm{ml})$ and $(R)-\mathrm{MTPACl} /$ $(S)$-MTPACl $(8.0 \mu \mathrm{l})$ were quickly added into the clean bottles, and all
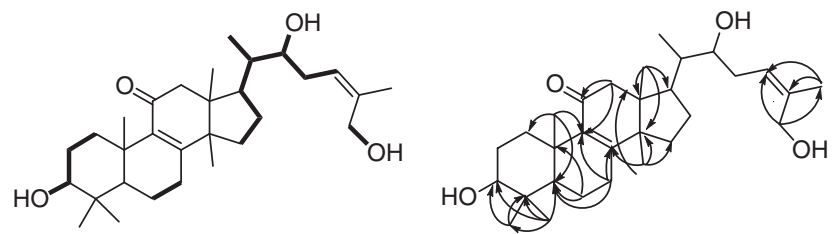

Figure $21 \mathrm{H}-1 \mathrm{H} \mathrm{COSY}$ and Key HMBC correlations for compound $\mathbf{1}$.

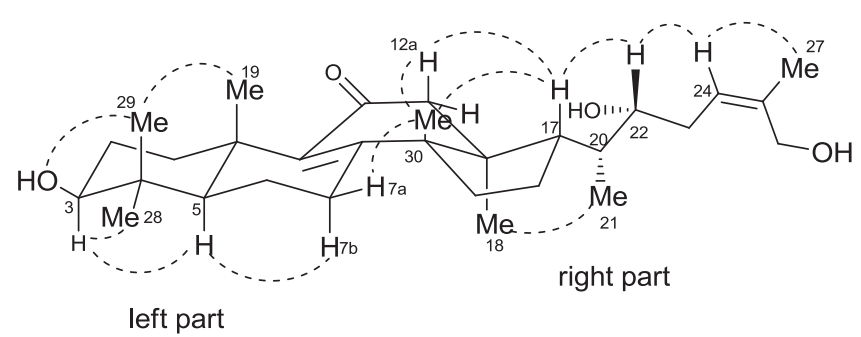

Figure $\mathbf{3}$ Key NOESY correlations for compound $\mathbf{1}$.

contents were mixed thoroughly by shaking the clean bottles carefully. The reaction was performed at room temperature, and the solution was allowed to stand for $24 \mathrm{~h}$. The S-MTPA ester and R-MTPA ester $(\mathbf{1} \mathbf{a} / \mathbf{1} \mathbf{b})$ were obtained by HPLC (Lumiere Tech Ltd., Berlin, Germany); YMC-Pack ODS-A column; $10 \mu \mathrm{m} ; 250 \times 10 \mathrm{~mm}$; $2 \mathrm{mlmin}^{-1}, 90 \% \mathrm{MeOH}$ in $\mathrm{H}_{2} \mathrm{O}$ for $2 \mathrm{~min}$, and followed by $90-100 \%$ for $10 \mathrm{~min})$ to obtain $\mathbf{1 a}$ and $\mathbf{1 b}\left(t_{\mathrm{R}} 23.8\right.$ and $\left.23.5 \mathrm{~min}\right)$, respectively.

3S, 22R, 26-trihydroxy-8, 24E-euphadien-11-one (1), was obtained as a colorless powder. It was assigned a molecular formula of $\mathrm{C}_{30} \mathrm{H}_{48} \mathrm{O}_{4}$ (seven degrees of unsaturation) on the basis of HRESIMS analysis $(\mathrm{m} / \mathrm{z}$ $\left.495.3462(\mathrm{M}+\mathrm{Na})^{+} ; \Delta-1.2 \mathrm{mmu}\right)$ and NMR data (Table 1). Analysis of the ${ }^{1} \mathrm{H},{ }^{13} \mathrm{C}$ and HMQC-NMR spectroscopic data (Supplementary Figures S1, S2 and S4) of 1 revealed the presence of seven methyl groups, nine methylene units (one of which is oxygenated), five methines (two of which are oxygenated), four quaternary carbons, four olefinic carbons (one of which is protonated) and one carbonyl carbon. These data accounted for all ${ }^{1} \mathrm{H}$ and ${ }^{13} \mathrm{C}$ resonances, and required 1 to be tetracyclic, which is consistent with the molecular formula $\mathrm{C}_{30} \mathrm{H}_{48} \mathrm{O}_{4}$. The planar structure was completely determined by $2 \mathrm{D}$ NMR including ${ }^{1} \mathrm{H}-{ }^{1} \mathrm{H}$ COSY and $\mathrm{HMBC}$ correlation spectra (Figure 2, Supplementary Figures S3 and S5).

Analysis of the ${ }^{1} \mathrm{H}-{ }^{1} \mathrm{H}$ COSY led to obtain four isolated fragments corresponding to C-1-C-3 (3-OH), C-6-C-7, C-15-C-17-C-20 (21$\left.\mathrm{CH}_{3}\right)-\mathrm{C}-22(22-\mathrm{OH})-\mathrm{C}-24$ and $\mathrm{C}-26-26-\mathrm{OH}$ (Figure 2). The connection of the four fragments was solved by HMBC correlations. The correlations from Me-19 to C-1, C-5 and C-10, from Me-28 and Me-29 to C-3, C-4 and C-5 established one cyclohexane ring (A ring). The HMBC correlation of Me-19 with C-5, C-10 and C-11, and of $\mathrm{H}_{2}-6$ with $\mathrm{C}-5$ and $\mathrm{C}-10, \mathrm{H}_{2}-7$ with $\mathrm{C}-8$ and C-9 led to form one cyclohexene ring (B ring) fused with $\mathbf{A}$ ring at $\mathrm{C}-5$ and $\mathrm{C}-10$. The distinct cross peaks in $\mathrm{HMBC}$ spectra from $\mathrm{H}_{2}-12$ to C-11, C-9, from Me-18 to C-12, C-13 and C-14, and from Me-30 to C-8, C-14 and C-15 completed the 2, 3, 3a, 4-tetrahydro- $1 \mathrm{H}$-inden-5(7aH)-one ring ( $\mathbf{C}$ and $\mathbf{D}$ rings), which was fused with the $\mathbf{B}$ ring at $\mathrm{C}-8$ and $\mathrm{C}-9$. The HMBC correlations from Me-27 to C-24, C-25 and C-26 confirmed that C-25 was connected with C-24, C-26 and C-27. Thus the planar structure for compound 1 was determined as shown in Figure 1. 


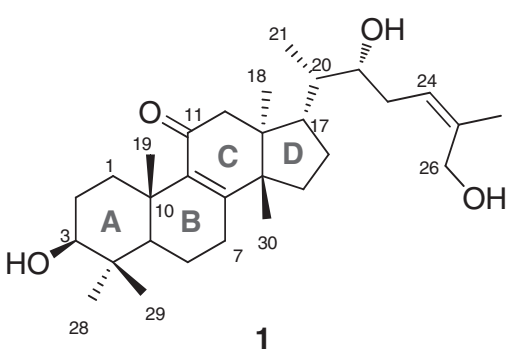

1

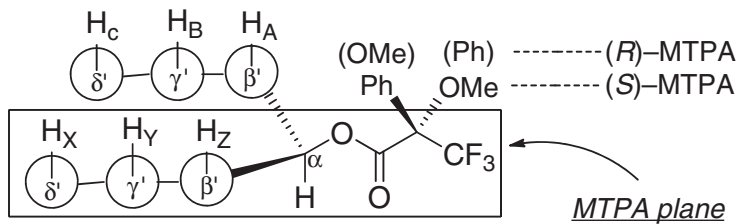

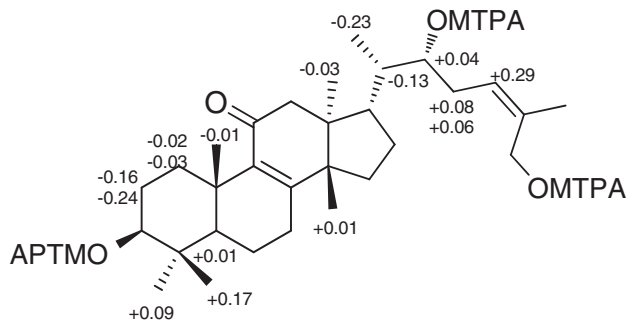

1a $\mathrm{R}=(S)$-MTPA ester

1b $\mathrm{R}=(R)$-MTPA ester

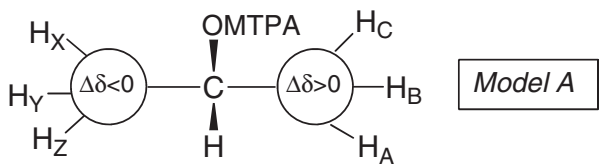

Figure $4 \Delta \delta$ values (in p.p.m.) $=\delta S-\delta$ R obtained for (S)- and (R)-MTPA esters 1a and 1 b. A full color version of this figure is available at The Journal of Antibiotics journal online.

The relative configuration was established by detailed analysis of NOESY correlation (Figure 3; Supplementary Figure S6). The NOESY correlation from the olefinic-proton H-24 to Me-27 confirmed the $Z$-configuration of the double bond. The correlation of H-3 with H-5 and Me-28, of Me-29 with Me-19 and 3-OH implied that $\mathrm{H}-3, \mathrm{H}-5$ and Me-28 had the same orientation, whereas Me-19 and $\mathrm{Me}-29$ were on the other side of the cyclohexane ring. Thus the relative configuration for the left part was solved. The cross peaks between Me-18 and Me-21, and between $\mathrm{H}-17$ and $\mathrm{H}-12 \mathrm{a}$, and Me30 and $\mathrm{H}-22$ in the NOESY spectra suggested that these protons were in closeness in space. Thus, the relative configuration for the rightpart of 1 was determined. The correlations from $\mathrm{H}-5$ to $\mathrm{H}-7 \mathrm{~b}$ and from Me-30 to H-7a led to the connection between the left and right parts, revealing that $\mathbf{1}$ possessed the same relative configuration as its analogs except for the additional 22-hydroxyl group (Figure 3). ${ }^{11}$ From the biosynthetic pathway, compound 1 might possess the same absolute configuration as its analogs. To support this hypothesis, modified Mosher's reaction (Figure 4) was used to determine the stereochemistry for C-3 and C-22. ${ }^{12}$ Treatment of 1 with (R)-MTPACl and (S)-MTPACl affords the S-MTPA ester (1a) and R-MTPA ester (1b), respectively. The ${ }^{1} \mathrm{H}$ NMR data (Supplementary Figures S7 and S9) revealed three methoxyl groups present in the target products, and the chemical shift values of $\mathrm{H}-3, \mathrm{H}-22$ and $\mathrm{H}_{2}-26$ were significantly down-field, which confirmed that $3-\mathrm{OH}, 22-\mathrm{OH}$ and $26-\mathrm{OH}$ all reacted with MTPACl. Analyzing the ${ }^{1} \mathrm{H}-{ }^{1} \mathrm{H}$ COSY data (Supplementary Figures S8 and S10) of the S-MTPA ester (1a) and R-MTPA ester (1b) gave the chemical shift values for $\mathrm{H}_{2}-1, \mathrm{H}_{2}-2, \mathrm{H}-3, \mathrm{H}-5, \mathrm{H}_{2}-6$, $\mathrm{H}_{2}-7, \mathrm{H}-17, \mathrm{H}-20, \mathrm{Me}-21, \mathrm{H}-21, \mathrm{H}_{2}-22, \mathrm{H}-23$ and $\mathrm{H}-24$, whereas ${ }^{1} \mathrm{H}-{ }^{1} \mathrm{H}$ COSY spectra could not afford the chemical shift values of the Me-18, Me-19, Me-28, Me-29 and Me-30, directly. After careful analysis and comparison of the ${ }^{1} \mathrm{H}$ NMR from $\mathbf{1}$, $\mathbf{1 a}$ and $\mathbf{1 b}$, the ${ }^{1} \mathrm{H}$ NMR signals of these methyl groups were obtained according to the following procedures. The basic mechanism of Mosher's reaction to determine the absolute configuration is due to the diamagnetic effect of the benzene ring, which leads to the down-/up-field change of nearby protons. Compared with other protons such as $\mathrm{H}_{2}-1, \mathrm{H}_{2}-2, \mathrm{Me}-28$, Me-29, Me-21, H-21, $\mathrm{H}_{2}-22, \mathrm{H}-23$ and H-24 (Supplementary Figure S11), the protons of Me-18, Me-19 and Me-30 were in long distance from MTPA esters at C-3 and C-22. Thus, the chemical shift values for these methyls
(Me-18, Me-19 and Me-30) changed little compared with other protons (above-mentioned) in the ${ }^{1} \mathrm{H}$ NMR spectra, whereas the distance between Me-28, Me-29 and the benzene ring in MTPA esters at C-3 was short, and the chemical shift values for these two methyls changed significantly. In addition, though the chemical shift values for these methyls changed in the ${ }^{1} \mathrm{H}$ NMR spectra of MTPA esters, the shapes (sharp or broad) of these did not change in $\mathbf{1}$ and $\mathbf{1 a} / \mathbf{1 b}$ (Supplementary Figure S11). Thus according to these procedures, the chemical shift values of Me-18, Me-19, Me-28, Me-29 and Me-30 were finally obtained (Supplementary Figure S11). The difference in chemical shift values $\left(\Delta \delta \delta_{S}-\delta_{R}\right)$ for the diastereomeric esters $\mathbf{1 a}$ and $\mathbf{1 b}$ was calculated in order to assign the absolute configuration at C-3 and C-22. Analysis of the relevant signals suggested $S$ and $R$ absolute configuration at C-3 and C-22 in 1, respectively (Figure 4). Considering that the relative configuration was determined by NOESY correlation, the stereochemistry of compound $\mathbf{1}$ was determined. In addition, the cytotoxic activities of $\mathbf{1}$ was assessed against A549, MDA-MB-231, PANC-1, human cancer cell lines by the MTT method with 5-fluorouracil (5-Fu) as the positive control. 3S, 22R, 26-trihydroxy-8, 24E-euphadien-11-one (1) displayed weak cytotoxic activities against the three cancer cell lines with $\mathrm{IC}_{50}$ values of $20.32,19.87$ and $30.45 \mu \mathrm{M}$, whereas $\mathrm{IC}_{50}$ values for 5 -Fu were $0.47,0.12$ and $0.67 \mu \mathrm{M}$, respectively.

\section{ACKNOWLEDGEMENTS}

We gratefully acknowledge the financial support from the National Natural Science Foundation of China (31000008), the Prize Fund for Excellent Middle Aged and Young Scientists of Shandong Province (BS2010HZ019), the Doctoral Prize of Shandong Academy of Sciences and the National S\&T Major Special Project on Major New Drug Innovation (2012ZX09301-002-004).

1 Suryanarayanan, T. S. et al. Fungal endophytes and bioprospecting. Fungal Biol. China Rev. 23, 9-19 (2009).

2 Aly., A. H., Debbab, A., Kjer, J. \& Proksch, P. Fungal endophytes from higher plants: a prolific source of phytochemicals and other bioactive natural products. Fungal Divers. 41, 1-16 (2010).

3 Ding, G. et al. Antifungal metabolites from the plant endophytic fungus Pestalotiopsis foedan. J. Nat. Prod. 71, 615-618 (2008).

4 Ding, G. et al. Pestalazines and pestalamides, bioactive metabolites from the plant pathogenic fungus Pestalotiopsis theae. J. Nat. Prod. 71, 1861-1865 (2008).

5 Ding, G. et al. Ambuic acid and torreyanic acid derivatives from the endolichenic fungus Pestalotiopsis sp. J. Nat. Prod. 72, 182-186 (2009). 
6 Ding, G. et al. Photinides A-F, cytotoxic benzofuranone-derived $\gamma$-lactones from the plant endophytic fungus Pestalotiopsis photiniae. J. Nat. Prod. 72, 942-945 (2009).

7 Ding, G. et al. Pestaloquinols A and B, isoprenylated epoxyquinols from Pestalotiopsis sp. J. Nat. Prod. 74, 286-291 (2011).

8 Izawa, Y. et al. Six new 10-pheynl-[11]cytochalasans, cytochalasins N-S from Phomopsis sp. Tetrahedron 45, 2323-2335 (1989).

9 Melissa, M. W. \& Jon, C. Dicerandrols, new antibiotic and cytotoxic dimers produced by the fungus Phomopsis longicolla isolated from an endangered mint. J. Nat. Prod. 64 1006-1009 (2001)
$10 \mathrm{Hou}$, Y. et al. Euphane triterpenoids of Cassipourea lanceolata from the Madagascar rainforest. Phytochemistry 71, 669-674 (2010).

11 Ohtani, I., Kusumi, T., Kashman, Y., Kakisawa, H. \& High-field, F. T. NMR applicaiton of Mosher's method. The abosoute configuration of marine terpenoids. J. Am. Chem. Soc. 113, 4092-4096 (1991).

12 Zheng, Y., Zhang, W., Ben, K. \& Wang, J. H. In vitro immunotoxicity and cytotoxicity of trichosanthin against human normal immunocytes and leukemia-lymphoma cells. Immunopharmacol. Immunotoxicol. 17, 69-79 (1995).

Supplementary Information accompanies the paper on The Journal of Antibiotics website (http://www.nature.com/ja) 